\title{
The effects of flunixin meglumine and hoof trimming on lying behavior, locomotion, and milk production in lame and nonlame lactating dairy cows
}

\author{
N. M. Chapel, ${ }^{*}$ J. M. Young, (1) and S. A. Wagnert (i) \\ Department of Animal Sciences, North Dakota State University, Fargo 58108
}

\begin{abstract}
Hoof trimming is used to prevent and treat lameness in dairy cows; however, hoof trimming itself increases daily time spent lying down, possibly due to discomfort. We hypothesized that treatment of lame and nonlame cows with an anti-inflammatory analgesic drug at the time of hoof trimming would mitigate discomfort, thereby improving locomotion scores and reducing post-trimming increases in lying time. We further hypothesized that drug treatment would improve post-trimming milk production. Our objective was to determine the effects of treatment with the nonsteroidal anti-inflammatory drug flunixin meglumine $(2.2 \mathrm{mg} / \mathrm{kg}$ of BW) at the time of hoof trimming on locomotion, lying times, and milk production in lame and nonlame lactating dairy cows. All cows were filmed for locomotion scoring $1 \mathrm{~d}$ before and 1, 8, and $28 \mathrm{~d}$ after hoof trimming. Daily time spent standing and lying was recorded for $4 \mathrm{~d}$ before and $4 \mathrm{wk}$ after hoof trimming, and daily milk production was recorded for $1 \mathrm{wk}$ before and $8 \mathrm{wk}$ after trimming. Thirty minutes before hoof trimming, an intravenous injection of flunixin meglumine $(\mathrm{n}=34)$ or isotonic sterile saline solution $(\mathrm{n}=$ 34) was administered to each cow. Then, all cows had their hooves trimmed using the Dutch method. The same treatment was repeated $24 \mathrm{~h}$ after hoof trimming. Cows were categorized using baseline locomotion scores as lame (score $\geq 3 / 5$ ) or nonlame (score $<3 / 5$ ). Drug treatment did not affect post-trimming changes in locomotion scores, daily lying times, or milk production. In both treatment groups, most cows had the same lameness status (lame or nonlame) at baseline and after treatment, and there was no difference between groups in the number of cows that changed lameness status over time. Lame cows $(\mathrm{n}=21)$ had no significant changes in lying times over the course of the study, whereas nonlame cows $(\mathrm{n}=47)$ had mean daily lying
\end{abstract}

Received December 4, 2018

Accepted February 9, 2020.

*Current address: Division of Animal Sciences, University of Missouri, Columbia 65211.

†Corresponding author: Sarah.Wagner@ndsu.edu times that were significantly higher than baseline all $4 \mathrm{wk}$ after trimming. Hoof trimming in nonlame cows should be scheduled for a time when increased lying behavior after trimming can be accommodated.

Key words: hoof trimming, flunixin meglumine, lameness

\section{INTRODUCTION}

Lameness in dairy cows causes predictable changes in behavior. Subjective locomotion scoring systems have been developed to quantify and assign degrees of severity to the changes in locomotion associated with lameness, including an arched back posture, decreased stride length, and asymmetrical leg speed (Sprecher et al., 1997; Flower and Weary, 2006). Lameness is also associated with increased time spent lying down each day; Chapinal et al. (2010b) found that nonlame cows spent an average of $12.2 \mathrm{~h}$ lying down each day, whereas lame cows spent $13.4 \mathrm{~h}$ lying down each day. Similarly, dairy cows in deep-bedded stalls with locomotion scores of at least 4 on a 5-point scale were found to lie down $1.6 \mathrm{~h}$ longer per day and have longer lying bouts than cows with locomotion scores of 3 or lower (Ito et al., 2010). Lameness also decreases milk production in affected cows (Archer et al., 2010).

In an effort to prevent and treat lameness, dairy herds typically practice regular hoof (claw) trimming. Dairy farms that trim cows' hooves on a yearly or biannual schedule have a lower prevalence of clinical lameness than herds trimmed only on an as-needed basis (Espejo and Endres, 2007), and consistent hoof trimming throughout a herd leads to a decrease in disease occurrence (Manske et al., 2002). Despite the beneficial preventive effects of hoof trimming, both lame and nonlame dairy cows have been found to spend more time lying down on the day of hoof trimming and for up to 5 wk afterward (Chapinal et al., 2010b,c), and dairy cows are less active on the day after hoof trimming (Van Hertem et al., 2014). Increased time spent lying down is associated with increased locomotion scores (Ito et al., 2010), and increased locomotion scores are associated with increased weight-shifting behavior, a marker of pain in lame cows (Chapinal et al., 2010a). This is a 
conundrum: hoof trimming, a procedure that has been found to reduce the incidence of painful lameness conditions, also provokes increased time spent lying down, a behavior that is associated with markers of lameness pain.

In human and veterinary medicine, there is evidence that providing pre-emptive analgesia before an intervention that is expected to be painful, such as surgery, decreases the development of pain during and after the intervention. A review of clinical trials in humans undergoing surgery found that the practice was beneficial in 6 of 8 studies using nonsteroidal anti-inflammatory drugs (NSAID) pre-emptively (Dahl and Moiniche, 2005). Ong et al.'s (2005) meta-analysis reviewed 66 randomized clinical trials including 3,261 human surgery patients and found that pre-emptive NSAID administration reduced total analgesic drug use and increased the time to the first postoperative analgesic request by patients, although postoperative pain scores were not affected. In cats undergoing onychectomy (declawing) and sterilization, Ingwersen et al. (2012) found that "patients that received meloxicam preoperatively had statistically better gait/lameness scores than those that received meloxicam postoperatively, supporting the principle of preemptive analgesia."

The hypothesis of the current study was that, similarly to human and feline patients undergoing surgery, a decrease in post-intervention pain might occur in dairy cows treated pre-emptively with an NSAID just before hoof trimming and be reflected in decreased locomotion scores or diminished lying times after trimming. Previous work provides support for this hypothesis; cows treated with the NSAID flunixin meglumine before hoof trimming had increased lying times for $2 \mathrm{~d}$ following hoof trimming, whereas saline-treated cows had increased lying times for the duration of the 5-d posttrimming observation period (Chapinal et al., 2010c). In addition, flunixin meglumine treatment without concurrent hoof trimming has been shown to reduce lameness pain in dairy cows when pain is measured using changes in weight-shifting behavior (Wagner et al., 2017). We further hypothesized that cows treated with flunixin meglumine at the time of hoof trimming would have improved milk production compared with control cows. The study objective was to determine the effects of flunixin meglumine treatment on locomotion scores, time spent lying, and milk production in lame and nonlame dairy cows after hoof trimming.

\section{MATERIALS AND METHODS}

All procedures involving animals were approved by the Institutional Animal Care and Use Committee at North Dakota State University.

\section{Animals and Housing}

Sixty-eight lactating Holstein cows from the North Dakota State University Teaching and Research Unit in Fargo, North Dakota, completed the study. Cows were housed in a mattress-bedded freestall barn with approximately 30 to 60 cows in each pen and a stocking density of less than 1 cow per stall. A TMR formulated to meet nutritional requirements for lactating dairy cows was fed ad libitum once daily at $0700 \mathrm{~h}$ and pushed up twice daily. Water was freely available from automatic waterers. Cows were milked twice daily at 0400 and $1500 \mathrm{~h}$ in a double-3 tandem parlor with automated milk weight recording for each cow at every milking (BouMatic LLC, Madison, WI).

\section{Enrollment}

The need for hoof trimming among eligible cows was determined by examining their locomotion, standing position, and claw length. Cows were enrolled if, in the judgement of farm management personnel and investigators, they had overlong claws or were lame (e.g., not bearing weight equally on all limbs or demonstrating abnormal stride length, arched back, or asymmetrical limb motion when walking). Cows were enrolled in 9 cohorts, each containing at least 7 cows, from August 2012 through July 2013, with enrollments in 2 out of 3 mo in each quarter of the year.

\section{Treatments}

Cows were blocked by day and assigned randomly to 1 of 2 treatments. Randomization was achieved by generating a random number list, sorting the cows to be enrolled in order of their ear tag number, and then matching the ear tag sequence to the random number sequence. Cows with an even random number corresponding to their ear tag number were assigned to the treatment group (FLU; n = 34) and treated with flunixin meglumine (Banamine, Merck Animal Health, Summit, NJ) at the highest labeled dose $(2.2 \mathrm{mg} / \mathrm{kg}$ of $50 \mathrm{mg} / \mathrm{mL}$ solution, $4.4 \mathrm{~mL} / 100 \mathrm{~kg}$ of BW). Those with an odd random number were assigned to the control group (SAL; $\mathrm{n}=34$ ) and treated with $4.4 \mathrm{~mL}$ of sterile isotonic saline solution/100 kg of BW. Treatments were given by injection into the jugular vein using a 20 -gauge, $3.81-\mathrm{cm}$ hypodermic needle less than $30 \mathrm{~min}$ before hoof trimming and repeated $24 \pm 2 \mathrm{~h}$ later using the contralateral jugular vein. Cows were weighed the day before treatment to ensure accurate calculation of treatment volumes. The hoof trimmer and cow handlers were masked to drug treatment group. 
Cows were restrained using a truck-mounted hydraulic tilt table during trimming by an experienced ( $>10 \mathrm{yr}$ ) hoof trimmer. First, trimming was performed when necessary using a grinding wheel and the Dutch method (Toussaint-Raven et al., 1985), in which the dorsal wall of each claw is trimmed to a length of approximately $7.5 \mathrm{~cm}$, and then the soles are reduced to consistent thickness, with care taken to preserve sole thickness at the heel. Cows had horn removed using a hoof knife to explore any areas of the sole that were underrun or otherwise appeared abnormal, and sole was pared away with the knife to ensure drainage and prevent accumulation of debris in cows with white line disease. Cows with digital dermatitis were treated with a paste made from tetracycline powder and water, and the lesion was covered with gauze and a cohesive wrap that was removed the following day. The times of day at which each cow entered and exited the tilt table and the lesions were observed by the hoof trimmer were recorded.

\section{Locomotion Scoring}

Cows were assigned locomotion scores using video recordings taken the day before hoof trimming, the day after hoof trimming, and 8 and $28 \mathrm{~d}$ after hoof trimming. Recordings were made using a digital camera (Canon PowerShot 110 HS, Canon Americas, Melville, NY). Without being touched by handlers, cows were encouraged to walk down an indoor feed alley with a floor made of nongrooved concrete. In each video, cows were recorded from the side while walking a minimum of 5 strides at a moderate pace; at least 3 videos were recorded per day for each cow. The videos were reviewed and the one in which each cow's locomotion was most easily evaluated was used for locomotion scoring. A research technician with training and practice in use of the numerical rating system who was masked to treatment assignments and video dates reviewed the videos and assigned locomotion scores using a 1-to-5 numerical rating system (where $1=$ no observable lameness and 5 $=$ severely lame). The observer assigned numerical rating system scores in half-point increments as described by Flower and Weary (2006) based on evaluation of these components of gait and posture: back arch, head bob, stride length, joint flexion, bilateral stride symmetry, and weight bearing.

\section{Lying Behavior}

Five to $7 \mathrm{~d}$ before treatment, cows were fitted with an accelerometer (Hobo Pendant G Data Logger, Onset, Cape Cod, MA) to record the amount of time spent standing and lying each day. The accelerometer was wrapped in cloth and secured to the cow's leg using veterinary cohesive wrap and tape. Accelerometers were placed on a rear leg in the milking parlor before milking. Leg choice was based on leg cleanliness and the absence of lesions or abrasions. In the case of moderately to severely lame cows, preference was given to the sound or less-lame rear leg. Accelerometers were attached on the lateral aspect of the cow's leg, between the hock and fetlock, to record orientation of the leg in 3 directional planes once per minute. The units were checked regularly to ensure that they were securely in place. Accelerometers were removed and replaced every 7 to $10 \mathrm{~d}$ to download recorded measurements and check the cows' legs for abrasions, lesions, or swelling. Experimental data for the days in which the accelerometers were reset were not included in data analyses because the data set was incomplete. Because of the amount of handling of the cows on the days of hoof trimming and drug treatment, lying time data for these days were not included in statistical analyses. Baseline lying data for analyses were therefore $\mathrm{d}-5$ to -2 , and post-treatment analyses of lying data began after the second drug treatment.

\section{Milk Production}

Milk production data were collected from the farm milking system for $1 \mathrm{wk}$ before hoof trimming and 8 wk afterward.

\section{Statistical Analyses}

Locomotion data were analyzed using PROC GLIMMIX in SAS (version 9.4; SAS Institute Inc., Cary, $\mathrm{NC}$ ). Cow was considered the experimental unit, time (relative to first injection and hoof trimming) as a repeated measure over cow, and daily enrollment cohort as a block. Different covariance structures were tested for the random statement to account for repeated measures on the same cow, and the best fit based on Akaike information criterion was chosen. Additionally, locomotion score, DIM, and parity on day of enrollment were included as covariates. A chi-squared test was used to determine whether the frequency of cows with a different lameness status or the same lameness status on $\mathrm{d}-1$ (baseline) and d 28 differed between treatments. Lying behaviors (daily lying time, lying bouts per day, and lying bout duration) and milk production data were analyzed using PROC MIXED in SAS with a repeated measures statement. A baseline value was calculated for each outcome variable and used as a covariate in the model. For locomotion scoring the baseline variable was the score on $\mathrm{d}-1$, for lying behaviors baseline was calculated from daily means on $\mathrm{d}-5$ through $\mathrm{d}-2$, and 
for milk production baseline was calculated using daily production means for the week before treatment. Baseline DIM and parity at enrollment were also included as covariates in each model. Baseline locomotion score (as an ordinal variable with 9 possible values from 1 to 5 with half integers, or as a binary variable that classified cows into lame or nonlame using the breakpoint locomotion score $\geq 3$ ) was included as a covariate for lying behavior and milk production models.

Two-way interactions between fixed effects and covariates were also tested and removed if $P>0.1$; the 2-way interaction of time and treatment was left in the model regardless of significance. Residuals were examined after each model to verify normality and homogeneity of variance. Lying behavior outcomes were analyzed as periodic daily averages over each of 4 weekly periods after treatment. Lying behaviors were analyzed across all cows and within lame and nonlame cows separately. Statistical significance was defined as any $P \leq 0.05$.

\section{RESULTS}

Seventy-four cows were enrolled in the study. Five cows did not complete the study procedures due to illness or injury unrelated to study procedures. In addition, 1 cow had an apparent allergic reaction to flunixin meglumine; she developed wheals on her legs, trunk, and neck within an hour of flunixin treatment. The cow was removed from the study and responded well to treatment with diphenhydramine. This resulted in 34 cows with complete data for each treatment group. Of the cows with complete data, in each treatment group 19 were primiparous and 15 were multiparous. At the time of enrollment, cows in the FLU group averaged $194 \pm 139$ DIM and weighed $666 \pm 76 \mathrm{~kg}$. Cows in the SAL group averaged $192 \pm 134$ DIM and weighed 682 $\pm 99 \mathrm{~kg}$.

\section{Locomotion Scores}

Locomotion score data are presented in Figure 1. Mean baseline locomotion scores were $2.61 \pm 0.11$ for SAL cows and $2.42 \pm 0.11$ for FLU cows $(P=0.20)$. Using baseline locomotion scores and a breakpoint of $\geq 3$ to classify a cow as lame, there were 11 lame and 23 nonlame cows in the FLU group and 10 lame and 24 nonlame cows in the SAL group.

We observed a treatment $\times$ time effect on mean locomotion scores. There were no differences in mean locomotion scores between SAL and FLU on d 1 and $8(P>0.41)$, but on d 28 SAL cows had a greater mean locomotion score compared with FLU cows (2.75 \pm 0.11 vs. $2.42 \pm 0.11$, respectively; $P=0.03$ ). In the
FLU group, 25 of 34 cows were in the same category (lame or nonlame) at baseline and at d 28, with 5 classified as lame and 16 as nonlame at all time points. In the SAL group, 26 of 34 cows were in the same category at baseline as at d 28, with 4 classified as lame and 14 as nonlame at all time points. No effect of treatment on the frequency with which cows increased, decreased, or maintained the same locomotion score was found when comparing $\mathrm{d}-1$ locomotion scores with scores at $\mathrm{d} 1$, 8 , or $28(P>0.25)$.

\section{Lying Behavior}

Daily Lying Time. Weekly means for daily lying time data are shown in Figures $2 \mathrm{a}$ and b. For all cows, we did not find an effect of drug treatment $(P>0.39)$, but there was an effect of time. Daily lying time was greater in the week after hoof trimming than in the week before hoof trimming $(P<0.01)$ and was not

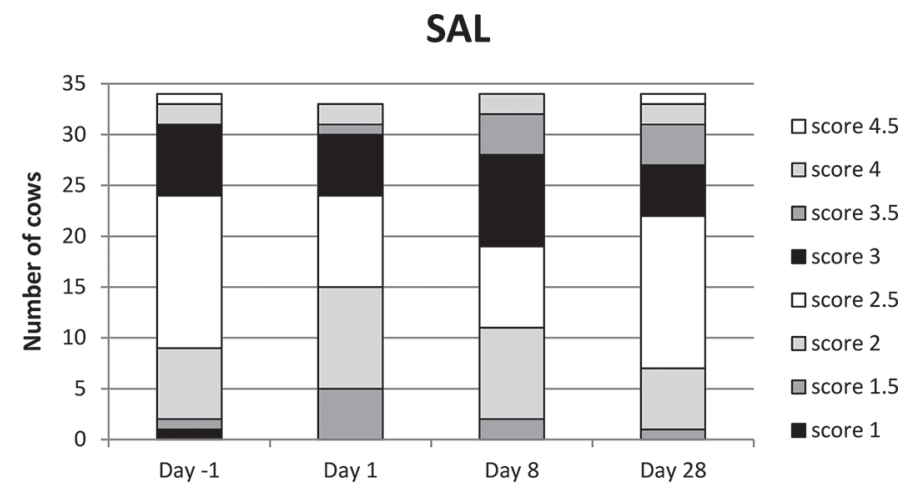

FLU

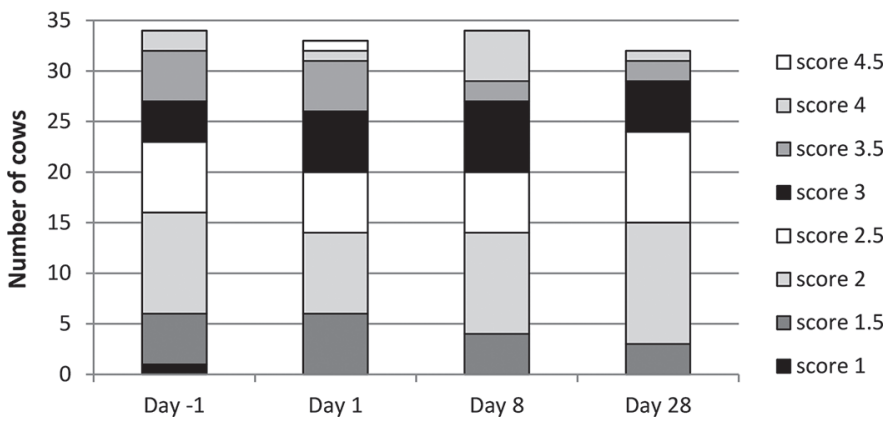

Figure 1. Locomotion scores on the day before hoof trimming (d -1 ), and 1,8, and $28 \mathrm{~d}$ after trimming for cows assigned to the control group (SAL; $\mathrm{n}=34$; treated with $4.4 \mathrm{~mL}$ of sterile isotonic saline solution/100 kg of BW) and cows assigned to the treatment group [FLU; $\mathrm{n}=34$; treated with flunixin meglumine (Banamine, Merck Animal Health, Summit, NJ) at the highest labeled dose $(2.2 \mathrm{mg} / \mathrm{kg}$ of $50 \mathrm{mg} /$ $\mathrm{mL}$ solution, $4.4 \mathrm{~mL} / 100 \mathrm{~kg}$ of BW)]. Locomotion was scored using a 1-to-5 numerical rating system, where $1=$ no observable lameness and $5=$ severely lame. 
a

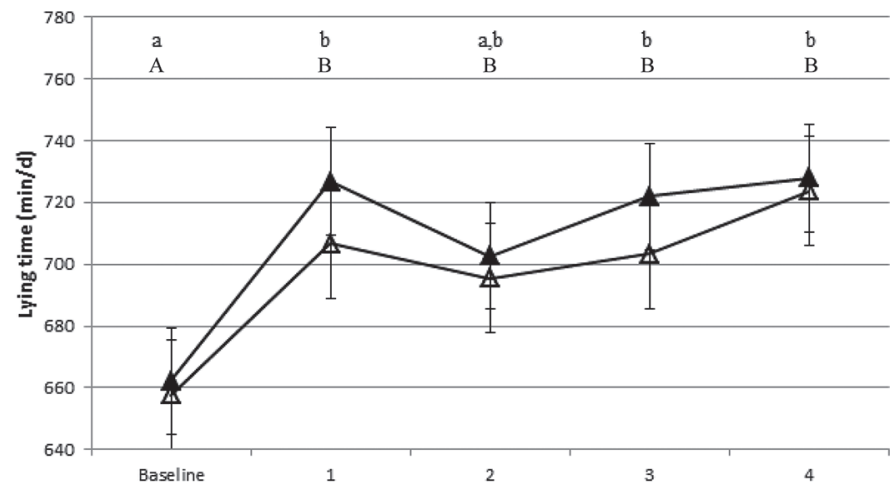

b

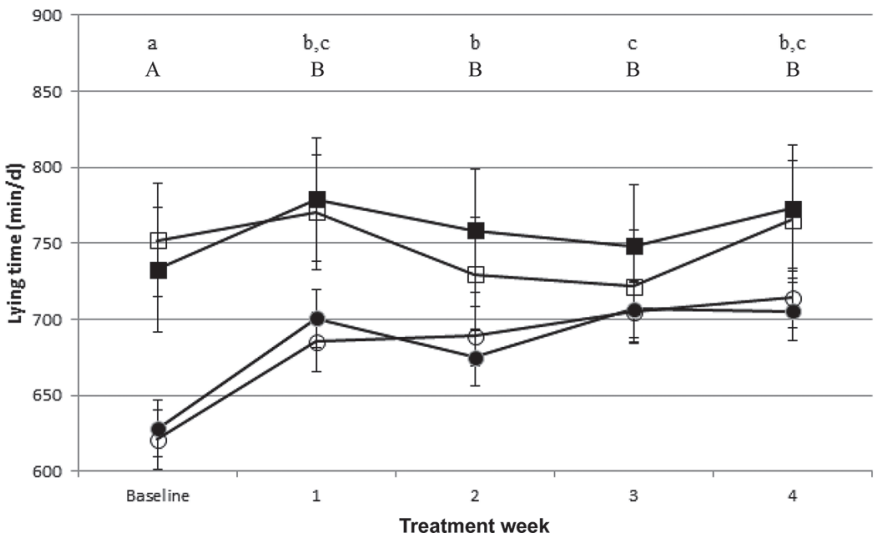

Figure 2. (a) Weekly means for daily lying time data for cows assigned to the control group (SAL; $\mathrm{n}=34$; treated with $4.4 \mathrm{~mL}$ of sterile isotonic saline solution/100 kg of BW; $\mathbf{\Delta}$ ) and those assigned to the treatment group [FLU; $\mathrm{n}=34$; treated with flunixin meglumine (Banamine, Merck Animal Health, Summit, NJ) at the highest labeled dose $(2.2 \mathrm{mg} / \mathrm{kg}$ of $50 \mathrm{mg} / \mathrm{mL}$ solution, $4.4 \mathrm{~mL} / 100 \mathrm{~kg}$ of BW); $\Delta$ ] at the time of hoof trimming and $24 \mathrm{~h}$ later. No differences between groups (treatment effects) were observed at any time $(P>0.05)$. Lying time was increased after trimming in both treatment groups (time effect). Time points with different lowercase letters $(\mathrm{a}, \mathrm{b})$ are different among SAL cows, and those with different uppercase letters $(\mathrm{A}, \mathrm{B})$ are different among FLU cows $(P \leq 0.05)$. (b) Weekly means for daily lying time data for SAL cows or FLU cows at the time of hoof trimming and $24 \mathrm{~h}$ later by pretreatment lameness status and treatment group $(\square=$ lame + FLU; $\bigcirc=$ nonlame + FLU; $\mathbf{\square}=$ lame + SAL; $\mathbf{0}$ = nonlame $+\mathrm{SAL})$. Among lame cows, there were no effects of treatment or time $(P>0.05)$. In nonlame cows, there were no effects of treatment $(P>0.05)$. Time effects were observed among nonlame cows; time points with different lowercase letters $(\mathrm{a}-\mathrm{c})$ are different for nonlame SAL cows $(\bullet)$, and those with different uppercase letters $(\mathrm{A}, \mathrm{B})$ are different for nonlame FLU cows $(O ; P \leq 0.05)$. Error bars represent SE.

different among the 4 weekly time points after hoof trimming $(P>0.07)$.

Among lame cows, neither between-group (treatment effect) nor within-group (time effect) differences in weekly means for daily lying time were observed $(P$ $>0.60$ and $P>0.08$, respectively). In nonlame cows, there was no drug treatment effect $(P>0.54)$, but there was an effect of time: daily lying times were greater than the baseline for the 4 wk following hoof trimming $(P \leq 0.05)$. In nonlame cows, there was no other time effect on lying time in the FLU group $(P>$ $0.20)$, whereas nonlame SAL cows had the additional time effect of lower daily lying times in wk 2 compared with wk $3(P=0.03)$.

Lying Bouts per Day. Mean daily lying bout data are shown in Figures $3 \mathrm{a}$ and b. For all cows, there was a treatment $\times$ time interaction: SAL cows had a greater mean number of lying bouts per day in wk 3 than FLU cows $(P=0.04)$. There were no treatment effects at other times $(P>0.21)$. A time effect was observed as all SAL cows had a higher number of lying bouts per day in wk 3 than in other weeks $(P<0.01)$; however, no other weeks differed for SAL cows $(P>0.12)$. Overall, no time effect was observed in mean daily lying bouts by week among FLU cows $(P>0.09)$.

Among lame cows, a treatment $\times$ time interaction was observed in wk 3 after trimming, when SAL cows had more lying bouts per day than FLU cows $(P=$ $0.01)$. The only time effect in lame cows occurred in wk 3 , when lame SAL cows had a greater mean number of lying bouts per day than during any other week $(P<$ 0.001). There were no other time effects on daily lying bouts for lame SAL or FLU cows $(P>0.49)$.

Among nonlame cows, no effects of treatment on daily lying bouts were observed $(P>0.30)$, nor were there any treatment $x$ time interactions. There were time effects within both nonlame groups. In the FLU nonlame group, the mean number of lying bouts per day was higher in the weeks after treatment than at baseline, with the mean number of bouts per day higher in wk 3 than in wk $2(P=0.03)$ and higher in wk 4 than in wk $1(P=0.05)$. In nonlame SAL cows, the mean daily number of lying bouts was greater in wk 3 than at baseline $(P=0.04)$.

Lying Bout Duration. Mean daily lying bout duration data are shown in Figures $4 \mathrm{a}$ and b. Among all cows, there was a treatment $\times$ time interaction, with mean lying bout duration being shorter in SAL cows than in FLU cows in the third week after trimming $(P=0.05)$. There were no differences between groups at other time points. There were no time effects on mean daily lying bout duration among weeks within the FLU group $(P>0.08)$. Among all SAL cows, there was a time effect of lower lying bout duration in wk 3 compared with all other weeks $(P<0.05)$ except wk 2 ; other weeks did not differ $(P>0.06)$.

Among lame cows, there was a treatment $\times$ time interaction at wk 3 after trimming, when SAL cows had shorter lying bouts than FLU cows $(P=0.04)$. The only time effect in lame cows was observed during wk 3, when SAL cows had shorter lying bouts than during any other week $(P<0.01)$; there were no differ- 
ences among the other weeks in that group $(P>0.08)$. Among nonlame cows, no treatment effects on lying bout duration were observed $(P>0.07)$. In nonlame FLU cows, there was a time effect, with lying bout duration being greater in wk 1 than baseline $(P=0.01)$ and no other within-group differences over time $(P>$ $0.17)$. There were no time effects on mean lying bout duration in nonlame SAL cows $(P>0.05)$.

a

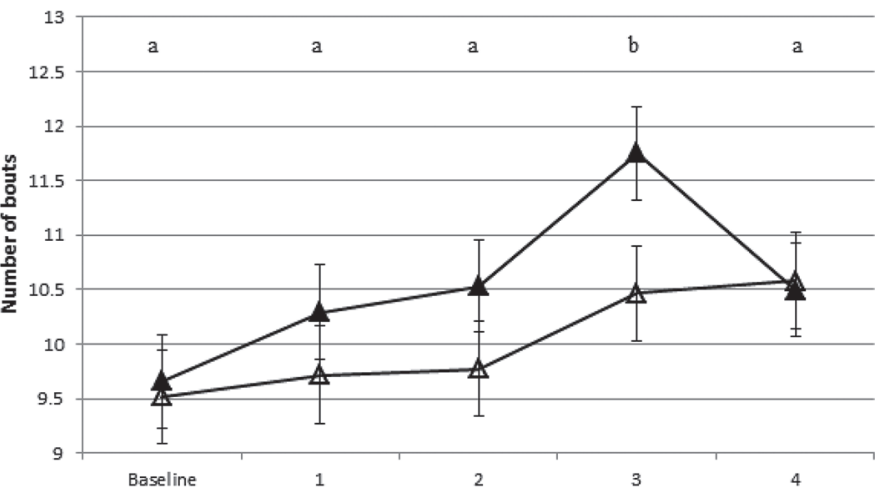

b

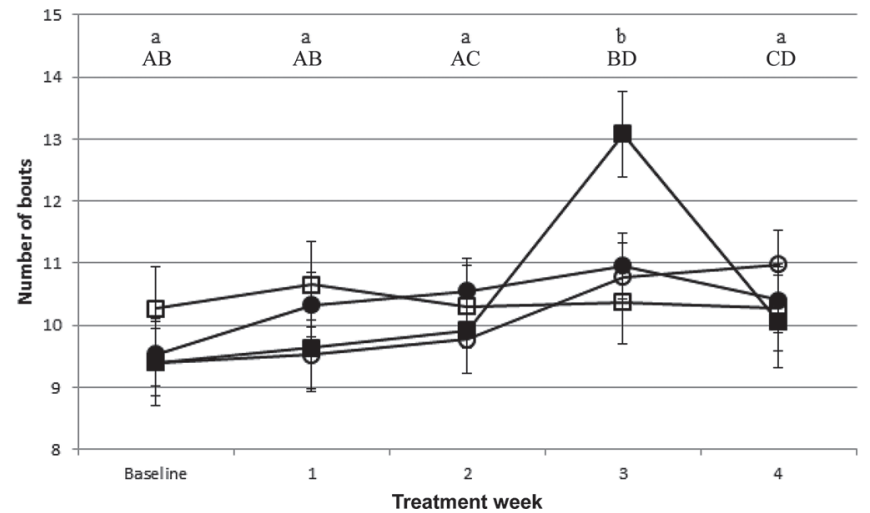

Figure 3. (a) Weekly mean number of lying bouts per day for cows assigned to the control group (SAL; $\mathrm{n}=34$; treated with $4.4 \mathrm{~mL}$ of sterile isotonic saline solution/100 $\mathrm{kg}$ of $\mathrm{BW} ; \mathbf{\Delta}$ ) and those assigned to the treatment group [FLU; $\mathrm{n}=34$; treated with flunixin meglumine (Banamine, Merck Animal Health, Summit, NJ) at the highest labeled dose $(2.2 \mathrm{mg} / \mathrm{kg}$ of $50 \mathrm{mg} / \mathrm{mL}$ solution, $4.4 \mathrm{~mL} / 100 \mathrm{~kg}$ of BW); $\Delta$ ] at the time of hoof trimming and $24 \mathrm{~h}$ later. There was a treatment $x$ time effect: SAL cows had more lying bouts per day in wk 3 than FLU cows $(P=0.040)$; there were not differences between treatment groups at other times $(P>0.05)$. There was no time effect in FLU cows $(P$ $>0.05)$, but there was an effect of time in SAL cows; time points with different lowercase letters $(\mathrm{a}, \mathrm{b})$ are different for SAL cows $(P \leq 0.05)$. (b) Weekly mean number of lying bouts per day for SAL cows or FLU cows at the time of hoof trimming and $24 \mathrm{~h}$ later by pretreatment lameness status and treatment group $(\square=$ lame + FLU; $\bigcirc=$ nonlame $+\mathrm{FLU} ; \boldsymbol{\square}=$ lame $+\mathrm{SAL} ; \boldsymbol{\bullet}=$ nonlame $+\mathrm{SAL})$. Among lame cows, a treatment $\times$ time interaction was observed in wk 3 after trimming, when SAL cows had more lying bouts per day than FLU cows $(P=$ 0.01). Among nonlame cows, no treatment effects were observed. Time effects were observed in lame SAL and nonlame FLU cows; time points with different lowercase letters $(\mathrm{a}, \mathrm{b})$ are different among lame SAL cows, and those with different uppercase letters (A-D) are different for nonlame FLU cows $(P \leq 0.05)$. Error bars represent SE.

\section{Milk Production}

There were no differences in milk production between treatment groups (treatment effects, $P=0.88$ ), nor were there time effects or treatment $\times$ time interactions $(P>0.05)$.

a

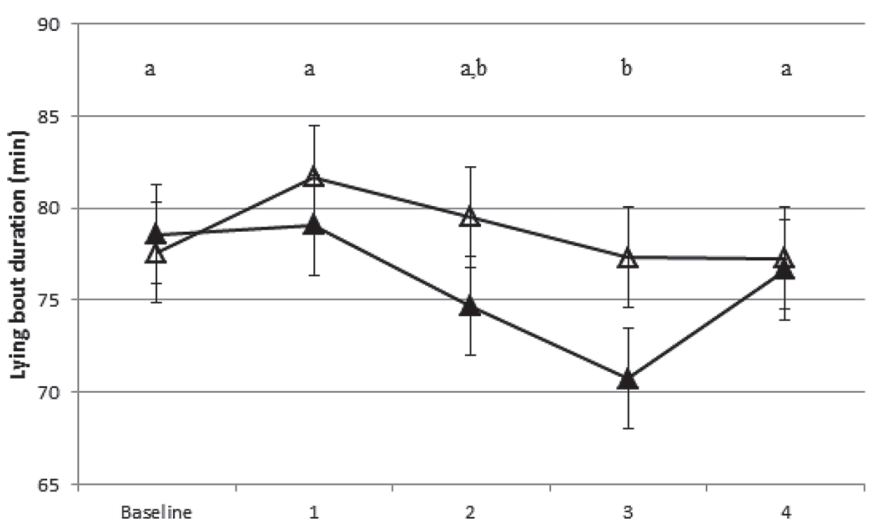

b

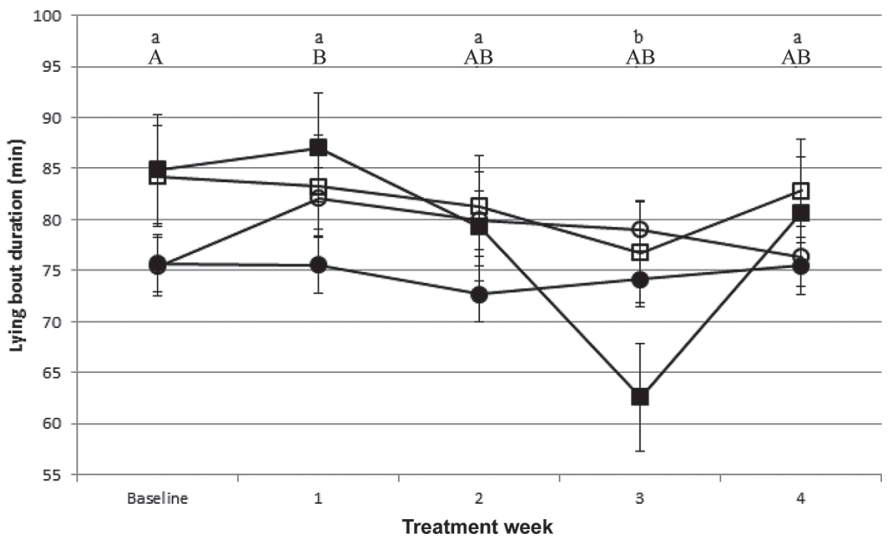

Figure 4. (a) Weekly mean lying bout duration for cows assigned to the control group (SAL; $\mathrm{n}=34$; treated with $4.4 \mathrm{~mL}$ of sterile isotonic saline solution/100 $\mathrm{kg}$ of $\mathrm{BW} ; \mathbf{\Delta}$ ) and those assigned to the treatment group [FLU; $\mathrm{n}=34$; treated with flunixin meglumine (Banamine, Merck Animal Health, Summit, NJ) at the highest labeled dose $(2.2 \mathrm{mg} / \mathrm{kg}$ of $50 \mathrm{mg} / \mathrm{mL}$ solution, $4.4 \mathrm{~mL} / 100 \mathrm{~kg}$ of BW); $\Delta$ ] at the time of hoof trimming and $24 \mathrm{~h}$ later. There was a treatment $\times$ time interaction in the third week after treatment: mean lying bout duration was longer in FLU cows than in SAL cows $(P=0.05)$; there were no differences between groups at other times. There were no effects of time within the FLU group, but there were time effects in the SAL group; time points with different lowercase letters $(\mathrm{a}, \mathrm{b})$ are different among SAL cows $(P \leq 0.05)$. (b) Weekly mean lying bout duration for SAL cows or FLU cows at the time of hoof trimming and $24 \mathrm{~h}$ later by pretreatment lameness status and treatment group ( $\square=$ lame + FLU; $\mathrm{O}=$ nonlame $+\mathrm{FLU} ; \boldsymbol{\square}=$ lame $+\mathrm{SAL} ; \boldsymbol{\bullet}=$ nonlame $+\mathrm{SAL})$. Among lame cows, there was a treatment $\times$ time interaction at wk 3 after trimming, when SAL cows had shorter lying bouts than FLU cows $(P=0.04)$. Among nonlame cows, there were no treatment effects, nor were there differences over time in the nonlame SAL cows $(P>0.05)$. Time effects were observed in lame SAL and nonlame FLU cows; time points with different lowercase letters $(\mathrm{a}, \mathrm{b})$ are different for lame SAL cows $(\mathbf{\square})$, and those with different uppercase letters $(\mathrm{A}, \mathrm{B})$ are different for nonlame FLU cows $(\mathrm{O} ; P \leq 0.05)$. Error bars represent SE. 


\section{Hoof Lesions}

Lesion data were recorded for 52 cows and are summarized in Table 1. There was a failure of lesion data recording for 16 cows. Of the cows for which lesion data were available, 16 had at least 1 visible lesion and 36 had no visible lesions. Lesions observed included white line disease, sole hemorrhage, abnormal claw growth ("corkscrew claw"), interdigital hyperplasia, interdigital dermatitis, and digital dermatitis. Two cows that had sole lesions (white line disease or sole bruising) were recorded as having 1 block (1 cow) or 2 blocks (1 cow) placed on opposing claws of the same limb.

Mean baseline locomotion score was $2.94 \pm 0.16$ for cows with visible hoof lesions, $2.31 \pm 0.10$ for cows without visible lesions, and $2.53 \pm 0.21$ for cows with no lesion data available. Among cows with observed lesions, 9 had baseline locomotion scores $\geq 3$ and 7 had baseline locomotion scores $<3$. Among cows with no lesions observed, 7 had a baseline score $\geq 3$, whereas 29 had scores $<3$. Among cows with no lesion data available, 5 had a baseline score $\geq 3$, whereas 11 had scores $<3$.

\section{DISCUSSION}

Our objective was to describe the effects of flunixin meglumine treatment around the time of hoof trimming on post-trimming locomotion scores, lying behavior, and milk production in lame and nonlame dairy cows. Although lying behavior was the primary outcome of interest in this study, we also evaluated locomotion scores because they are a commonly used proxy for lameness pain in research studies and welfare audit programs involving dairy cows. We found that locomotion scores after hoof trimming were not meaningfully reduced by drug treatment, with the only treatment effect observed at d 28, when the difference between group mean scores was 0.14 point greater than the baseline difference in means on a 5-point scale. Although the effect was statistically significant, the clinical importance of this finding is probably nil. Additionally, comparison of the treatment groups based on changes in lameness status over the 28-d period following hoof trimming revealed no effect of treatment. In both treatment groups, most cows did not change lameness status based on locomotion score, changes that did occur went in both directions (lame to not lame and not lame to lame), and there was no difference in the pattern of changes between groups. These outcomes agree with earlier findings that flunixin treatment, with or without concurrent hoof trimming, does not affect locomotion scores (Chapinal et al., 2010c; Wagner et al., 2017).
Table 1. Observed lesion data (number of claws/number of cows) for 52 cows $^{1}$

\begin{tabular}{lll}
\hline Lesion type & SAL & FLU \\
\hline Interdigital hyperplasia & $3 / 2$ & $1 / 1$ \\
White line disease & & \\
Block placed & $2 / 1$ & $1 / 1$ \\
No block & $0 / 0$ & $1 / 1$ \\
Sole hemorrhage & & \\
Block placed & $0 / 0$ & $1 / 1$ \\
No block & $0 / 0$ & $7 / 4$ \\
Digital dermatitis & $8 / 5$ & $2 / 2$ \\
Interdigital dermatitis & $1 / 1$ & $1 / 1$ \\
Abnormal claw growth & $0 / 0$ & $2 / 2$ \\
\hline
\end{tabular}

${ }^{1} \mathrm{SAL}=$ cows treated with $4.4 \mathrm{~mL}$ of sterile isotonic saline solution $/ 100$ $\mathrm{kg}$ of BW. FLU = cows treated with flunixin meglumine (Banamine, Merck Animal Health, Summit, NJ) at the highest labeled dose (2.2 $\mathrm{mg} / \mathrm{kg}$ of $50 \mathrm{mg} / \mathrm{mL}$ solution, $4.4 \mathrm{~mL} / 100 \mathrm{~kg}$ of $\mathrm{BW}$ ).

Hoof trimming also failed to improve locomotion scores in this study, in agreement with previous work. For example, Van Hertem et al. (2014) found that the percentage of cows with scores $\geq 3$ on a 5 -point scale (the same breakpoint we used to define lame cows) increased from $14 \%$ to $34 \%$ within 3 d after hoof trimming and remained higher than baseline for at least 2 mo. García-Muñoz et al. (2017) concluded that hoof trimmer intervention to treat cows defined as lame using the same criterion did not improve locomotion. Chapinal et al. (2010b) also found that most lame and nonlame cows had the same or increased locomotion scores after trimming.

Lying behavior was also unaffected by drug treatment, but it was affected by hoof trimming. This is consistent with 2 studies by Chapinal et al. (2010b,c), in which lame and nonlame cows had increased lying times following hoof trimming, and with the observation by Van Hertem et al. (2014) that lame and nonlame cows exhibited decreased activity after trimming. We found that hoof trimming did not affect lying time in cows that were already lame; this may be because trimming does not change the degree of lameness pain in such cows, or it may be that the effects of hoof trimming are not large enough to be reflected in altered lying times in lame cows. The time budgets of lame cows may not have allowed for further increases in lying time after trimming. By contrast, among cows that were not lame, time spent lying down increased after hoof trimming and remained elevated over baseline levels for the entire 4 -wk post-treatment observation period.

The hypothesis that increased lying times in dairy cows are the result of pain is supported by combining the observations that increased lying time and higher locomotion scores are correlated (Ito et al., 2010) and that higher locomotion scores correlate with increased weight-shifting behavior that indicates pain (Chapinal 
et al., 2010a; Wagner et al., 2017). Our hypothesis that NSAID treatment would reduce lying times after hoof trimming was based on the idea that hoof trimming itself causes a painful reaction in the limb, demonstrated by increased time spent lying down afterward, that could be mitigated using an analgesic anti-inflammatory drug. Our findings neither confirm nor refute the presence of a painful response after hoof trimming. It is possible that the drug and dosing regimen we used were not effective or that the methods we used to measure outcomes, lying times and locomotion scores, were not sufficiently sensitive to detect an analgesic effect of the drug. Why daily lying time after hoof trimming was increased in our study and in others remains unknown. Perhaps adjusting to a new pastern angle and sole thickness, as cows often have to do after trimming, is painful. It is also possible that some of the effects seen after hoof trimming have to do with activities that surround hoof trimming, including increased standing times, being away from the home pen, and stressful handling.

One aspect of lying behavior we observed is not easily explained. In the third week following hoof trimming, lame cows treated with saline solution had a higher mean number of lying bouts and lower mean lying bout duration than they had during any other week. The increased number of bouts was balanced by the decreased duration of bouts such that the mean daily lying time was not different from the weeks before and after. No particular cow or cohort was found to be responsible for the change in lying patterns. A possible reason might be if several cows in that group experienced estrus during the third week after hoof trimming; this idea is strictly speculative.

Two previous studies involving the interplay of hoof trimming and drug treatment have been reported. Miguel-Pacheco et al. (2016) identified new cases of lameness based on increased locomotion scores and the presence of a sole lesion and then treated the cows with therapeutic hoof trimming alone, trimming in combination with the NSAID ketoprofen or a hoof block on the opposing claw, or hoof trimming in combination with both drug treatment and a hoof block. In cows treated with trimming and a hoof block, lying time was increased in the $5 \mathrm{~d}$ after trimming, whereas lying time did not change significantly after treatment in the other 3 groups. Thomas et al. (2015) performed a study using the same treatment groups that evaluated outcomes based on locomotion scores instead of lying times and found that cows treated with therapeutic trimming, hoof block, and an NSAID had a significantly higher rate of return to normal locomotion $(56.1 \%)$ than did cows that were treated only with therapeutic trimming ( $24.4 \%$ cure rate); the other treatment groups had rates of improvement intermediate between the trimmingonly group and trimming, block, and NSAID group. These 2 studies both described some benefit of ketoprofen treatment of lame cows in combination with trimming and a hoof block when evaluated using lying times and locomotion as outcomes. Ketoprofen and flunixin meglumine (with no other treatment) have both been found to alleviate lameness pain when pain is measured using changes in weight-shifting behavior (Chapinal et al., 2010a; Wagner et al., 2017), but of the 2 drugs, only ketoprofen has previously been found to improve locomotion scores in lame cows when drug treatment was the only intervention (Flower et al., 2008). Our failure to observe a benefit of flunixin meglumine treatment around the time of trimming may be because the drug's analgesic and anti-inflammatory effects are not large enough to be detected using locomotion scoring and lying behavior as outcome measures.

We did not observe any effect of drug treatment or hoof trimming on milk production, which has not been a measured outcome in previous studies of the effects of NSAID treatment combined with hoof trimming. This lack of effects is unsurprising; many factors affect milk production in dairy cows, and any single factor would have to have a large effect to produce a measurable change.

In addition to testing our hypotheses about the effects of flunixin meglumine on locomotion, lying behavior, and milk production after hoof trimming, this study provides new information about the relationship between visible hoof lesions, measures of lameness, and hoof trimming. In agreement with previous research, the relationship between visible lesions and locomotion scores in our study was not consistent. Cows that had lesions were usually lame (9 of 16), and cows that did not have lesions were usually not lame (29 of 36); however, we also enrolled 7 cows that were lame but did not have hoof lesions and 7 cows that had hoof lesions but were not lame. Similarly, Groenevelt et al. (2014) found that $6.6 \%$ of moderately lame cows had severe hoof lesions (sole ulcers or toe necrosis), whereas O'Callaghan et al. (2003) found that cows with apparently severe foot lesions did not always show obvious lameness and Maselyne et al. (2017) found no differences in lying times among groups of cows categorized as having mild, moderate, or severe lesions. Cows with hoof lesions and cows with lameness (abnormal locomotion) are not exactly the same population, nor do they necessarily respond in the same way to hoof trimming. Maselyne et al. (2017) found increased lying time after trimming in cows with lesions but not in cows without lesions, whereas we found increased lying time after trimming in nonlame cows but not in cows with lameness. The differences in the implications of visible lesions and 
abnormal locomotion, and the inconsistent correlation between the 2, may be explained in part by the lag in time between the beginning of the process that generates lesions (and pain) and the point at which they become visible to an observer as well as by the neural "wind-up" and hyperalgesia associated with chronicity (Whay et al., 1998), which may lead to pain that is more severe and long-lasting than the presence of lesions would suggest. At the same time, some lesions seem to cause less pain than one would expect based on their appearance. It is possible that some cows are less perceptive of pain than others, or that healing or adaptation may sometimes take place before lesion resolution is observable.

Overall, the results of this study demonstrate no meaningful effect of flunixin meglumine treatment at the highest US product label dose on locomotion, lying behavior, or milk production after hoof trimming in lame and nonlame dairy cows. Hoof trimming was found to increase lying times in nonlame cows. It is prudent to perform hoof trimming of nonlame cows at times when increased time spent lying afterward can be accommodated.

\section{ACKNOWLEDGMENTS}

This project was funded by Merck Animal Health (Summit, NJ). The authors thank Matt Larson (Larson Hoof Trimming, Detroit Lakes, MN), Leah Maertens (North Dakota State University, Fargo), and Núria Chapinal (University of British Columbia, Vancouver, BC, Canada) for technical and statistical assistance. The authors have not stated any conflicts of interest.

\section{REFERENCES}

Archer, S. C., M. J. Green, and J. N. Huxley. 2010. Association between milk yield and serial locomotion score assessments in UK dairy cows. J. Dairy Sci. 93:4045-4053. https://doi.org/10.3168/ jds.2010-3062.

Chapinal, N., A. M. de Passillé, and J. Rushen. 2010b. Correlated changes in behavioral indicators of lameness in dairy cows following hoof trimming. J. Dairy Sci. 93:5758-5763. https://doi.org/10 $.3168 / \mathrm{jds} .2010-3426$.

Chapinal, N., A. M. de Passillé, J. Rushen, and S. A. Wagner. 2010a. Automated methods for detecting lameness and measuring analgesia in dairy cattle. J. Dairy Sci. 93:2007-2013. https://doi.org/10 $.3168 /$ jds.2009-2803.

Chapinal, N., A. M. de Passillé, J. Rushen, and S. A. Wagner. 2010c. Effect of analgesia during hoof trimming on gait, weight distribution, and activity of dairy cattle. J. Dairy Sci. 93:3039-3046. https: //doi.org/10.3168/jds.2009-2987.

Dahl, J. B., and S. Moiniche. 2005. Pre-emptive analgesia. Br. Med. Bull. 71:13-27. https://doi.org/10.1093/bmb/ldh030.

Espejo, L. A., and M. I. Endres. 2007. Herd-level risk factors for lameness in high-producing Holstein cows housed in freestall barns. J. Dairy Sci. 90:306-314. https://doi.org/10.3168/jds.S0022 -0302(07) 72631-0.

Flower, F. C., M. Sedlbauer, E. Carter, M. A. G. Von Keyserlingk, D. J. Sanderson, and D. M. Weary. 2008. Analgesics improve the gait of lame dairy cattle. J. Dairy Sci. 91:3010-3014. https://doi.org/ 10.3168/jds.2007-0968.

Flower, F. C., and D. M. Weary. 2006. Effect of hoof pathologies on subjective assessments of dairy cow gait. J. Dairy Sci. 89:139-146. https://doi.org/10.3168/jds.S0022-0302(06)72077-X.

García-Muñoz, A., N. Singh, C. Leonardi, and N. Silva-del-Río. 2017. Effect of hoof trimmer intervention in moderately lame cows on lameness progression and milk yield. J. Dairy Sci. 100:9205-9214. https://doi.org/10.3168/jds.2016-12449.

Groenevelt, M., D. C. J. Main, D. Tisdall, T. G. Knowles, and N. J. Bell. 2014. Measuring the response to therapeutic foot trimming in dairy cows with fortnightly lameness scoring. Vet. J. 201:283-288. https://doi.org/10.1016/j.tvjl.2014.05.017.

Ingwersen, W., R. Fox, G. Cunningham, and M. Winhall. 2012. Efficacy and safety of 3 versus 5 days of meloxicam as an analgesic for feline onychectomy and sterilization. Can. Vet. J. 53:257-264.

Ito, K., M. A. G. von Keyserlingk, S. J. LeBlanc, and D. M. Weary. 2010. Lying behavior as an indicator of lameness in dairy cows. J. Dairy Sci. 93:3553-3560. https://doi.org/10.3168/jds.2009-2951.

Manske, T., J. Hultgren, and C. Bergsten. 2002. The effect of claw trimming on the hoof health of Swedish dairy cattle. Prev. Vet. Med. 54:113-129. https://doi.org/10.1016/s0167-5877(02)00020-x.

Maselyne, J., L. Munksgaard, M. Pastell, V. M. Thorup, A. Van Nuffel, S. Van Weyenberg, and P. T. Thomsen. 2017. The presence of hoof lesions affects lying and standing duration around trimming. Pages 195-196 in Proc. 19th International Symposium and 11th Conference: Lameness in Ruminants, Munich, Germany.

Miguel-Pacheco, G. G., H. J. Thomas, J. Kaler, J. Craigon, and J. N. Huxley. 2016. Effects of lameness treatment for claw horn lesions on lying behaviour in dairy cows. Appl. Anim. Behav. Sci. 179:11-16. https://doi.org/10.1016/j.applanim.2016.04.001.

O'Callaghan, K. A., P. J. Cripps, D. Y. Downham, and R. D. Murray. 2003. Subjective and objective assessment of pain and discomfort due to lameness in dairy cattle. Anim. Welf. 12:605-610.

Ong, C. K. S., P. Lirk, R. A. Seymour, and B. J. Jenkins. 2005. The efficacy of preemptive analgesia for acute postoperative pain management: A meta-analysis. Anesth. Analg. 100:757-773. https:// doi.org/10.1213/01.ANE.0000144428.98767.0E

Sprecher, D. J., D. E. Hostetler, and J. B. Kaneene. 1997. A lameness scoring system that uses posture and gait to predict dairy cattle reproductive performance. Theriogenology 47:1179-1187. https:// doi.org/10.1016/s0093-691x(97)00098-8.

Thomas, H. J., G. G. Miguel-Pacheco, N. J. Bollard, S. C. Archer, N. J. Bell, C. Mason, O. J. R. Maxwell, J. G. Remnant, P. Sleeman, H. R. Whay, and J. N. Huxley. 2015. Evaluation of treatments for claw horn lesions in dairy cows in a randomized controlled trial. J. Dairy Sci. 98:4477-4486. https://doi.org/10.3168/jds.2014-8982.

Toussaint-Raven, E., R. T. Halstra, and D. J. Peterse. 1985. Cattle Foot Care and Claw Trimming. Farming Press, Ipswich, UK.

Van Hertem, T., Y. Parmet, M. Steensels, E. Maltz, A. Antler, A. A. Schlageter-Tello, C. Lokhorst, C. E. B. Romanini, S. Viazzi, C. Bahr, D. Berckmans, and I. Halachmi. 2014. The effect of routine hoof trimming on locomotion score, ruminating time, activity, and milk yield of dairy cows. J. Dairy Sci. 97:4852-4863. https://doi .org/10.3168/jds.2013-7576.

Wagner, S. A., J. M. Young, J. K. Tena, and B. H. Manning. 2017. Behavioral evaluation of the analgesic effect of flunixin meglumine in lame dairy cows. J. Dairy Sci. 100:6562-6566. https://doi.org/ 10.3168/jds.2016-12331.

Whay, H. R., A. E. Waterman, A. J. F. Webster, and J. K. O'Brien. 1998. The influence of lesion type on the duration of hyperalgesia associated with hindlimb lameness in dairy cattle. Vet. J. 156:2329. https://doi.org/10.1016/s1090-0233(98)80058-0.

\section{ORCIDS}

J. M. Young (๑) https://orcid.org/0000-0002-3171-9187

S. A. Wagner (ํ) https://orcid.org/0000-0002-4046-7583 